\title{
HIV and schistosomiasis coinfection in African children
}

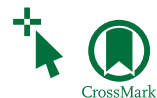

Amaya Bustinduy, Charles King, Janet Scott, Sarah Appleton, José Carlos Sousa-Figueiredo, Martha Betson, *J Russell Stothard

HIV/AIDS and schistosomiasis both cause a great disease burden in sub-Saharan Africa, and the two diseases share substantial overlap in their epidemiological characteristics. Although disease-specific control interventions are continuing, potential synergies in the control efforts for these two diseases have not been investigated. With a focus on children with schistosomiasis, we assess the risk for increased HIV transmission, HIV progression, and impaired response to drugs when given alongside HIV interventions. A new research agenda tailored to children is needed to better understand the interactions of these two diseases and the potential for combined responses.

\section{Introduction}

HIV and schistosomiasis are two of the most widespread infections worldwide; nonetheless, their combined effect has not been fully delineated, especially in sub-Saharan Africa. Although both diseases differ in their presentation, manifestations, and treatment, there is substantial geographical overlap in the poorest countries where endemicity is often high (figure 1). ${ }^{1}$ For example, in Ethiopia, Nigeria, South Africa, Zambia, and Zimbabwe, adult HIV prevalence ranges from $15 \%$ to $28 \%$, and the prevalence of schistosomiasis commonly exceeds $50 \%$ in high-risk rural communities. ${ }^{2}$ The prevalence of HIV and schistosomiasis might be even higher in data-deficient areas such as Madagascar or Mozambique. ${ }^{3}$

As the HIV pandemic progresses, interventions against the increase in HIV-related disease have focused on universal access to highly active antiretroviral therapy (HAART). Many children in sub-Saharan Africa present for care late in their HIV disease progression, ${ }^{4}$ and there are nearly 1000 new cases of paediatric HIV infection every day-more than 2.5 million children younger than 15 years have HIV/AIDS. ${ }^{3}$ WHO guidance ${ }^{5,6}$ emphasises the importance of prompt diagnosis, treatment, and monitoring of HIV in children. Although there is a strong commitment from the international community to eliminate new childhood HIV infections by 2015, the HIV epidemic in sub-Saharan Africa shows little sign of abatement.

Schistosomiasis, either urogenital or intestinal, is a chronic inflammatory disease caused by a water-borne parasitic blood fluke. In sub-Saharan Africa, 220 million people are infected with the parasite, and even more are at risk, mainly children. ${ }^{2}$ Although congenital transmission does not occur, exposure and infection can take place very soon after birth, depending on an infant's environmental exposure to parasite-infested water. Until recently, the burden of disease from these early exposures was overlooked. However, infants and preschool-age children (aged 1-5 years) can have active disease ${ }^{8,9}$ and have poor access to deworming treatment because current measures are focused on preventive chemotherapy (ie, mass drug administration of praziquantel to school-age children aged 6-15 years).$^{10}$ Praziquantel is a safe and affordable oral drug that is active against all forms of schistosomiasis and can be given by non-medical personnel. ${ }^{11}$ As new information emerges about schistosomiasis in early childhood, international policies and practices are beginning to respond to this unmet need [A: "inequity" has a specific meaning in the global health context, and don't think the phrase is appropriate here, does "unmet need" work, or could you suggest an alternative phrase?]. ${ }^{12,13}$

Identification of disconnects in combined control HIV control has only a short history, whereas schistosomiasis is an old disease,$^{14}$ for which the inability to implement fully integrated preventive strategies because of shortfalls in water hygiene and sanitation has led to the dominance of preventive chemotherapy as the most cost-effective option. Locally applicable and integrated interventions tailored to the immediate epidemiological setting are desirable. Intricate understanding of the transmission biology, epidemiology, and social patterning (ie, HIV largely by sexual behaviour and schistosomiasis by water contact) of the diseases is needed.

Environmental risk factors for both infections include restricted access to safe water, low socioeconomic status, and poor educational access..$^{15}$ HIV transmission risk is made up of complex individual behaviours, including commercial sex work, intravenous drug use, and various unsafe exposures to blood and other bodily fluids; in subSaharan Africa lack of autonomy for women and intolerance of male homosexuality are important factors. ${ }^{16}$ The social context of schistosomiasis is very different, but relates to unsafe exposures that are repeated often during domestic tasks or employment. Schistosomiasis is typically highly prevalent in fishing communities in which To further complicate control, each disease agent has ecological and genetic diversity, with potential to adapt to control interventions. ${ }^{18}$

Although multidisease approaches are being promoted by WHO (eg, in management of HIV and malaria), related platforms for research and operational control of HIV and schistosomiasis simply do not exist. ${ }^{19}$ There is also little room for future optimism because the newly created Disease Reference Group of Helminthic Infections for the control and elimination of helminthiasis in people has not adopted a multipleendemic-disease approach within their framework. . $^{18}$

The first cases of HIV/AIDS in adults were described in $1981,{ }^{20}$ and 5 years lapsed before evidence of routes other than sexual transmission emerged and paediatric HIV/ opportunities for HIV transmission can also be raised. . $^{15,17}$
Parasitology Department, Liverpool School of Tropical Medicine, Liverpool, UK (A Bustinduy, JC Sousa-Figueiredo, Prof J R Stothard); Center for Global Health and Diseases, Case Western Reserve University, Cleveland, $\mathrm{OH}$, USA (C King); [A: please provide affiliation for Janet Scott.] (I Scott); School of Clinical Medicine, University of Cambridge, Cambridge, UK (S Appleton); and Departmen of Production and Population Health, Royal Veterinary College, Hatfield, UK (M Betson) Correspondence to: ProfJ Russell Stothard, Parasitology Department, Liverpool School of Tropical Medicine, Liverpool L35QA, UK jrstoth@liverpool.ac.uk 


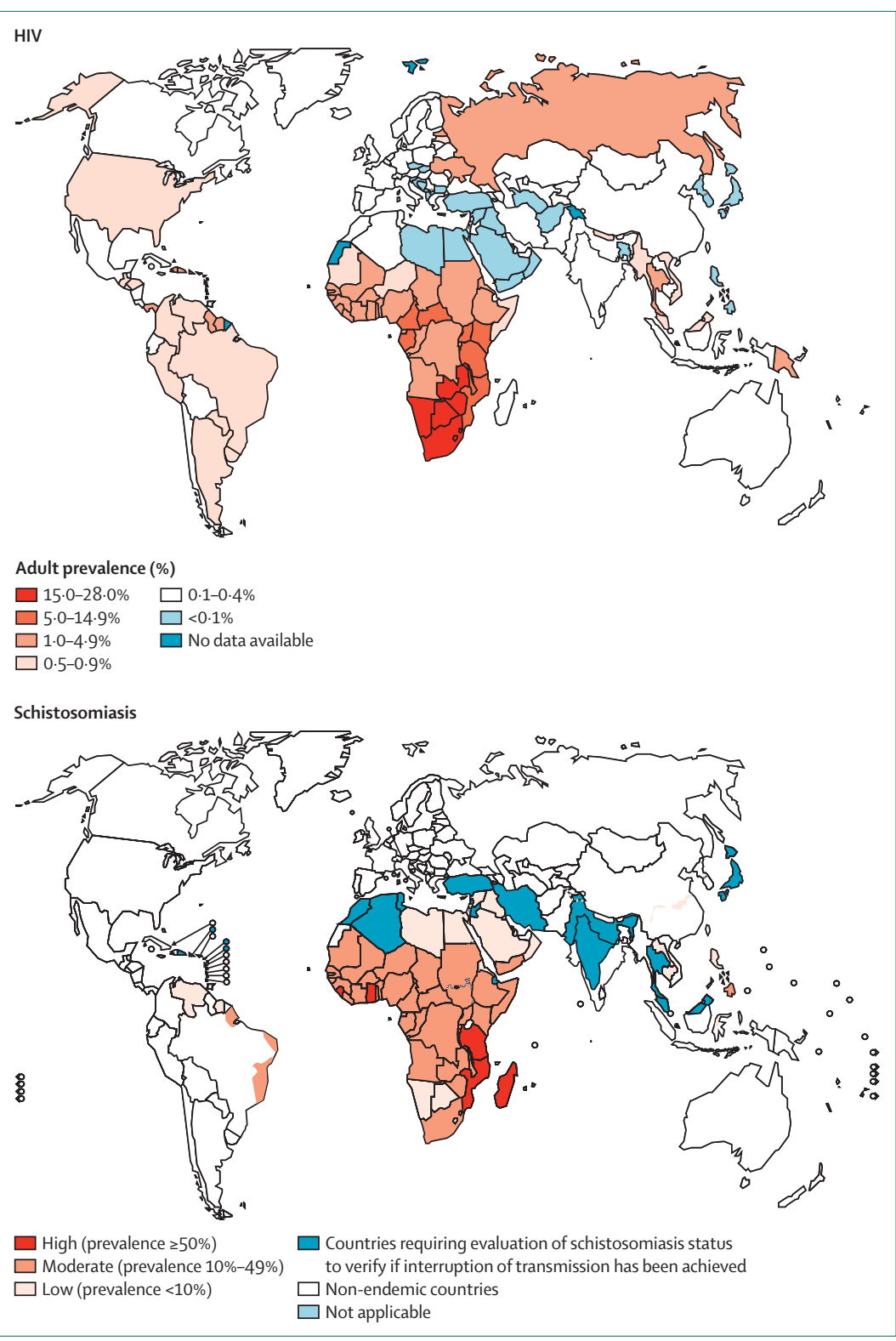

Figure 1: Global adult prevalence of HIV and schistosomiasis

Different forms of schistosomiasis—urogenital and intestinal-are aggregated including adults and school-age children. Dual schistosome infections have not yet been fully estimated nor are prevalences of coinfections with HIV known. Data from WHO.

See Online for appendix

AIDS was recognised..$^{21}$ The importance of mother-to-child transmission of HIV has only slowly become a public health priority.7 Alongside this focus, and with much less 50 political advocacy, the case for prevention of schistosomiasis in early childhood is only now beginning. ${ }^{8,22-24}$ Moreover, as the subtly disabling morbidities associated with chronic schistosomiasis are being better recognised in this age group, an imperative for early prevention and control is 55 becoming much clearer. ${ }^{25-29}$

Both diseases are difficult to diagnose in early
1 childhood, and studies of HIV and schistosomiasis coinfection have been limited to adults. ${ }^{30.31}$ Paediatric studies (except for maternal-child health research) typically lag behind those in adults, ${ }^{32}$ and estimation of 5 true burden of disease becomes a challenge because of an absence of paediatric diagnostics in resource-poor areas (appendix pp xxx [A: please add page numbers for table 1 in the appendix]..$^{33}$

\section{Reconnection of the importance of HIV and schistosomiasis coinfection}

Given the potentially overwhelming burden of disease caused by dual infection, there are growing efforts to study the interactions between HIV and schistosomiasis, 15 especially in areas where dual endemicity is most prevalent. ${ }^{3437}$ Researchers doing experimental studies in animals are trying to understand the pathogenesis and immune responses when both infections are present. ${ }^{38,39}$ Investigators have done clinical studies of responses to 20 antiparasitic and antiretroviral therapy for HIV/AIDS disease progression..$^{40-43}$ However, all of these clinical studies exclusively targeted individuals older than 18 years, and thereby overlooked interactions in childhood. Attempting to bridge this knowledge gap for 25 childhood HIV and schistosomiasis co-infection, we reviewed the most relevant epidemiological and experimental studies to develop a conceptual framework (figure 2) that identifies the transmission and later manifestations of disease in early life alongside current 30 recommendations for treatment and integrated national control programmes.

\section{Vertical HIV transmission}

The close associations between mothers and their 35 unborn children begin an intricate interplay of antigen exposure and immune-response modification that continues throughout childhood. This interplay might lead to increased susceptibility to certain diseases and decreased cognition; all of which are known downstream 40 effects in children born to women with malaria or advanced $\mathrm{HIV}^{26,44,45}$ but are not yet known in children born to women with both HIV and schistosomiasis. HIV transmission from infected mothers to children can occur through three different routes: intrauterine (5-10\% 45 [A: of transmissions, or of children with mothers with HIV? If transmissions, should the total percentages make up $100 \%$ ?]), during delivery (15-30\%), or through breastfeeding (5-30\%). ${ }^{46}$ Prepartum maternal helminth infections have been linked to increased mother-to-child transmission of $\mathrm{HIV}^{47}$ but lesions from female genital schistosomiasis are possibly also important.

WHO advocates universal HAART of all pregnant women with HIV, irrespective of their CD4 cell counts, but this target is far from a reality in resource-poor subSaharan Africa.? The lack of consistent HAART for pregnant women is one of the major hurdles to controlling HIV-transmission. Alongside HAART 


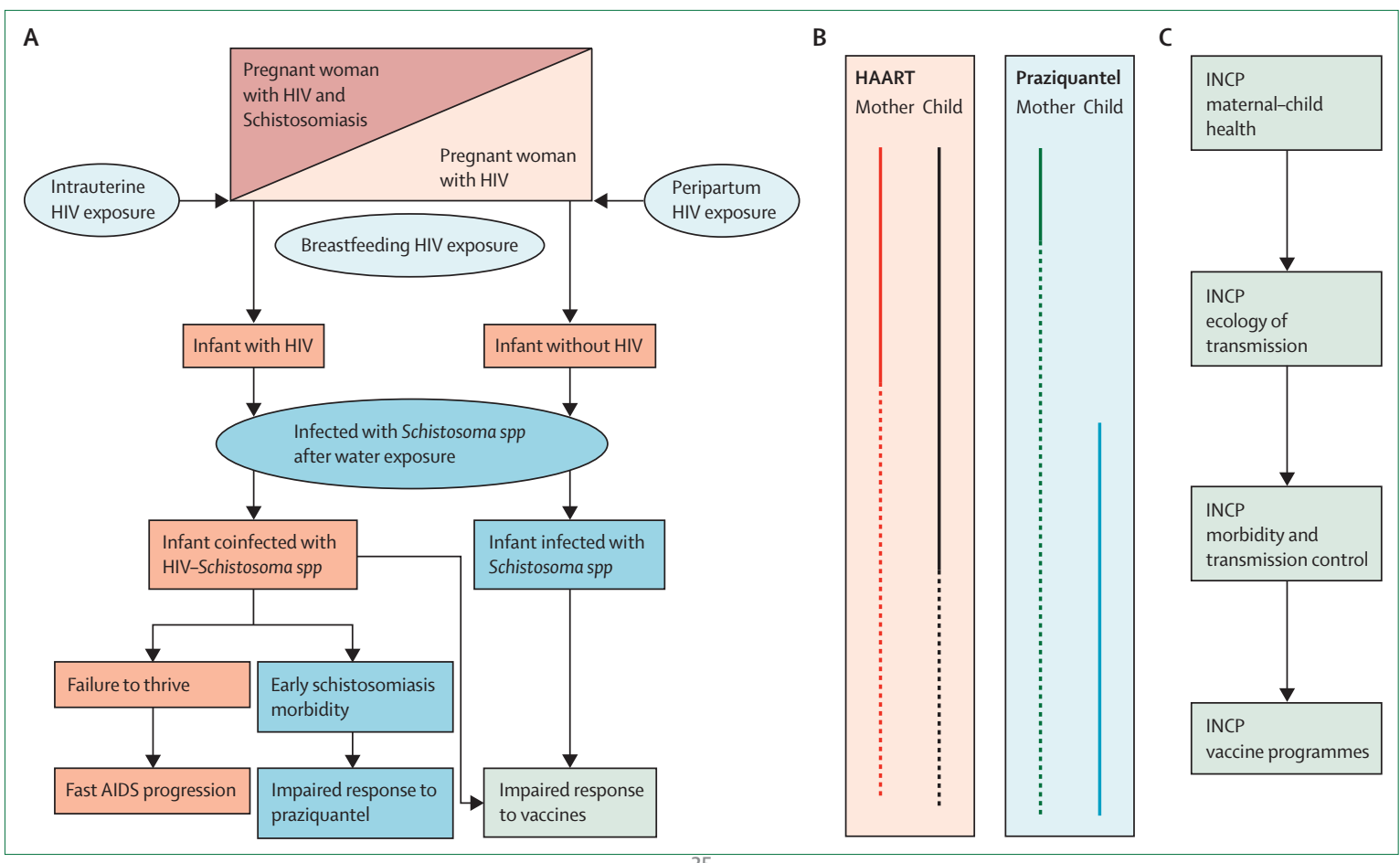

Figure 2: Conceptual framework of the epidemiology of HIV and schistosomiasis coinfection, dual treatment, and proposed control with national guidelines and interventions

(A) Proposed pathophysiological mechanism of mother-to-child transmission in pregnant women with one infection (HIV) or two infections (HIV and

schistosomiasis). (B) Highly active antiretroviral therapy (HAART) and praziquantel treatment guidelines as recommended by WHO. Solid line indicates continued treatment. Dotted line indicates treatment based on CD4 cell coun ang linical staging [A: ok?]. All pregnant women (M) are encouraged to start HAART (even if not indicated on the basis of CD4 cell counts) and to continue through ildren (Ch) born to women with HIV are to start HAART for 6 weeks, irrespective of their HIV status, since it is a difficult period to ascertain infection, particularly in resource-poor areas. (C) Integrated National Control Programmes should tailor their efforts on the basis of in-country prevalence. Programmes should use national health policies that include efforts to control HIV, schistosomiasis, other helminths and neglected transmitted diseases, and malaria. Different integrated programmes can include those for maternal-child health, transmission, and ecology of transmission that could target social and environmental determinants for all diseases (ie, water sanitation, sexual education and womens' capacity development, and vector control). PZQ=praziquantel. INCP=Integrated National Control Programmes.

antiparasitic treatment (with praziquantel, albendazole, or ivermectin) has the possible beneficial effect of lowering HIV viral load. ${ }^{48}$ However, the researchers who reported this benefit did not find consistent HAART 40 availability for participants, and future studies should adopt full treatment of HIV and parasite as standard.

\section{Differences between children and adults}

Extrapolation of knowledge and recommendations from 45 adult health interventions into paediatric settings often has a so-called little adults approach. For HIV and schistosomiasis coinfection, this approach is especially flawed in research and policy. For example, children have a larger surface-to-volume ratio with higher metabolic 5 rate, oxygen consumption, and caloric requirements than adults, not only to maintain homoeostasis, but also to grow and develop. Typically children need more food per kilogram of bodyweight than do adults. ${ }^{49}$ Consequently, children are particularly susceptible to any 5 growth deficits caused by infections or reduced nutrient intake, and growth-faltering states are particularly associated with diseases such as HIV/AIDS ${ }^{50}$ and schistosomiasis, ${ }^{27,51}$ moreover, these infections might have synergistic interactions that amplify their individual 0 effects.

Drugs are often more widely distributed around children's bodies than in adults and organ blood volumes are also higher. ${ }^{52}$ In schistosomiasis, this pattern could be highly relevant if blood flow to the liver is increased, as this would lead to swift clearance of praziquantel and a strong pharmacodynamic argument to challenge dosing recommendations directly extrapolated from adults (ie, $40 \mathrm{mg} / \mathrm{kg}$ ). Other unanswered questions include how HIV infection or continuing HAART might change praziquantel efficacy after consideration that praziquantel's antischistosomal activity is immunedependent..$^{53}$ Thus, the context, timing, and progression of each infection is important.

\section{HIV precedes schistosomiasis in children}

HIV infection in infants and young children is nearly always vertically transmitted; thus HIV infection precedes 
schistosomiasis (figure 2), whereas in adult-acquired 1 study in Zimbabwe provided evidence to the contrary. ${ }^{37}$ infection the reverse is often true (table). ${ }^{54}$ This distinction is very important because the parasitic infection (schistosomiasis) in adult-acquired HIV has intrinsically different immunopathological and immune-modulating 5 p effects, which probably shape the pattern of disease. To our knowledge, this concept has not been investigated clinically; however, investigators of two studies of animals have attempted to assess it for retroviral replication and worm reduction after praziquantel treatment. ${ }^{38,39}$ Rhesus 10 macaques carrying a latent chronic simian-human immunodeficiency virus (SHIV) infection (in analogy with HIV) were infected with cercariae of Schistosoma mansoni and had an increase in SHIV replication and faster disease progression than had animals without intestinal schisto- 15 somiasis. ${ }^{39}$ In the other study, T-cell-depleted mice infected with $S$ mansoni and later treated with two antischistosomal drugs (praziquantel and oxamniquine) had little worm clearance compared with mice with a healthy immune system,$^{38}$ confirming the important role of host immunity 2 in drug action. Thus, if severely immune-suppressed people respond to treatment in the same way, particularly those with AIDS, then antischistosomal treatment is likely to have reduced effectiveness. Although there are no studies of people to corroborate this finding, serial 2 retreatment studies of adults with HIV who were at high risk of $S$ mansoni suggest that adults with more years of parasite exposure in childhood (hence more potential for established antiparasite immune responses) have longer infection-free periods after praziquantel treatment. ${ }^{55}$ However, because of the scarcity of evidence, such generalised conjectures should be viewed with caution (appendix pp xxx) [A: please add page numbers for table 2 in appendix].

\section{Schistosomiasis precedes HIV in adults}

In endemic areas, as part of daily water contact, individuals typically contract schistosomiasis during childhood, with subsequent activation of the immune system by antigen-specific and non-specific immunomodulation biasing towards a T-helper-cell 2 polarity, potentially increasing susceptibility to viral and mycobacterial infections. Later HIV infection might also change the host-parasite immune balance. Epidemiological studies of adults in the Democratic Republic of 4 the Congo, Ethiopia, and Kenya show a decrease in schistosome-egg excretion for those who acquired HIV later in life. ${ }^{34-36} \mathrm{~A}$ fully competent T-cell population might be needed to augment schistosome-egg excretion, or perhaps worm fecundity, although reports of a cohort

\begin{tabular}{|lll|}
\hline & HIV & Schistosomiasis \\
\hline Adult & Older than 14 years & Age 2-5 years \\
Child & Birth or infancy & Younger than 2 years \\
\hline Table: Common age of primary infection of HIV and schistosomiasis
\end{tabular}

Nonetheless children's expected response to egg excretion in the presence of HIV is unknown. Results of targeted epidemiological surveys have shown a high percentage of the infants and preschool-age children assessed were shedding eggs, ${ }^{8,9,22,24,56}$ but studies have not investigated the HIV status of examined children. For example, children with lower or intermittent egg output might have a very light intensity infection or they might have compromised immune systems from HIV infection (or other immune deficiencies), which impairs efficient egg excretion and, for this reason alone, HIV infection should be considered as a possible contributing factor to rate of egg excretion.

Effect of coinfection on mortality and morbidity HIV infection remains a major public health threat in sub-Saharan Africa with 1.3 million deaths attributed to AIDS every year; ${ }^{3}$ at least $5 \%$ of all disability-adjusted lifeyears (DALYs) lost in low-income and middle-income countries are believed to be due to HIV/AIDS. ${ }^{57}$ A drawback of the DALY is that the effect of comorbidities is overlooked, ${ }^{58}$ formally bottlenecking the scope of health research and intervention programmes. The real context of HIV in sub-Saharan Africa is one in which children have two or more concurrent parasites in addition to their chronic HIV infection. For example, results of two paediatric cohort studies in South Africa ${ }^{59}$ and Zambia ${ }^{60}$ identified female sex, young age (younger than 2 years), severe wasting, and anaemia as mortality risk factors for children with HIV. ${ }^{59,60}$ Although schistosomiasis was not included as a comorbidity in either study, it can contribute to wasting and anaemia ${ }^{51,61-64}$ and is present in both countries..$^{65,66}$ The potential 35 detrimental synergy between HIV and schistosomiasis will be most severe in early childhood due to metabolic insults during key periods of growth and development.

Several studies from schistosomiasis-endemic countries have shown severe morbidity with end-organ fibrosis in children, disorders that were previously thought to be clinically relevant only during adulthood. ${ }^{67}$ Whether coinfected children are more or less at risk of end-organ fibrosis caused by schistosomiasis is unknown, but we hypothesise that children with HIV have less ultrasound-detectable fibrosis but more liver cellular damage, putting them at greater risk of liver dysfunction and failure. This damage could be caused by T-cell dysregulation, fuelled by HIV infection, preceding the onset of schistosomiasis-related hepatosplenic disease. This progression is, of course, not the case in adults, because liver pathology caused by schistosomiasis is already underway when HIV infection is acquired..$^{68,69}$ Research to assess the severity of schistosomiasis alongside HIV is clearly needed.

\section{Is AIDS linked with schistosomiasis in coendemic areas?}


There has been much discussion about whether schistosomiasis increases susceptibility to HIV; in Malawi where urogenital schistosomiasis is common, an increased susceptibility to HIV transmission among women has been suggested by the patterns of submucosal inflammation found around parasite eggs in cervicovaginal biopsy samples. ${ }^{70,71}$ Studies in Kenya and Uganda, where intestinal schistosomiasis is common, have shown immune-modulation of anti-HIV responses in patients with schistosomiasis, including decreased production of interleukins 4 and 10 compared with that in individuals without $\mathrm{HIV}^{72}$ and decreased cytolytic CD8 T-cell response to viral antigens when both HIV infection and schistosomiasis were present. ${ }^{73}$

The risk of HIV transmission might be increased by 15 inflammation in the female genital tract from urogenital schistosomiasis, women in Tanzania and Zimbabwe with female genital schistosomiais have an increased age-adjusted rate of HIV infection compared with those without female genital schistosomiais. ${ }^{7476}$ The effect of 2 maternal female genital schistosomiasis on HIV transmission, during parturition example, is not known. Additionally, men with uro $\&$ al schistosomiasis in Madagascar had substantial damage to their reproductive tracts, ${ }^{\pi}$ with increased amounts of leucocyte 2 and proinflammatory cytokine in semen. ${ }^{78}$ As with other proinflammatory sexually transmitted infections, urogenital schistosomiasis in both sexes could increase HIV transmission as children enter puberty and become sexually active.

Babies of mothers who have both HIV and other common helminthic infections (lymphatic filariasis, urogenital schistosomiasis, and hookworm) during pregnancy are more likely to have HIV 1 year after birth than are babies born to mothers with HIV alone. ${ }^{47}$ The risk of intrauterine, perinatal, or breast-feeding-related mother-to-child HIV transmission might be increased by substantial immune-modulation in utero during the development of a doubly exposed fetus, rendering the baby more susceptible to viral infections.

A more rapid progression of HIV infection with preexisting schistosomiasis seems likely because a 17-timeslower viral inoculum of SHIV was sufficient to infect rhesus macaques with intestinal schistosomiasis via mucosal exposure, as compared with the dose needed to infect controls without intestinal schistosomiasis. ${ }^{79}$ In mice, T-regulatory cell upregulation, which occurs in schistosomiasis, can inhibit the ability of CD8 cells to control viral replication and, if similar in human beings, could potentially increase HIV progression with 5 concurrent schistosomiasis..$^{80}$ Mice with schistosomiasis have increased concentrations of arginase- 1 in macrophages, and the arginase- 1 in macrophages and neutrophils in individuals with HIV might worsen immune hyporesponsiveness, increasing opportunistic infections. ${ }^{81,82}$ The presence of increased HIV receptors on CD4 cells in patients with intestinal schistosomiasis further raises opportunity for HIV transmission and progression..$^{83}$

\section{Treatment with praziquantel \\ The effect of HIV}

The effectiveness of praziquantel is dependent on adequate blood concentrations of the drug and on presence of an intact and robust immune system ${ }^{84}$ parasitological cure in T-cell-depleted mice with intestinal schistosomiasis is decreased compared with infected controls. ${ }^{38}$ Initial action of praziquantel against adult worms is associated with tegumental disruption and later synergy with an effective antibody-mediated immune attack. ${ }^{84}$ By contrast, studies of adults with HIV suggest that early immune-suppression does not adversely affect antischistosomal treatment with praziquantel, with no difference noted in parasitological cure rates between patients with HIV and those without in Kenya, Zambia, and Zimbabwe (appendix pp xxx [A: please add page number for table 3 in the appendix. Please supply the appendix with table 3 included]). ${ }^{43,85,86}$ However, effects of antiparasitic treatment on HIV-related markers are not clear because a 2009 meta-analysis showed some benefit for deworming in the prevention of HIV progression after pooling randomised trial data. ${ }^{87}$ When data for observational studies were included in the analysis, the apparent deworming effect was not as strong. ${ }^{88}$ Most surprisingly perhaps, no study has yet investigated treatment of both HIV and schistosomiasis with 30 antiretroviral drugs as part of the regimen. In Zimbabwe, an unblinded randomised controlled trial showed a decrease in viral load and an increase in CD4 cell counts among adults who received early praziquantel treatment, as compared with those who were treated 3 months after diagnosis. ${ }^{89}$ Results of a double-blind, placebo-controlled, trial of multiple helminth coinfections in a cohort of pregnant women in Uganda showed no difference in viral load between women with HIV given praziquantel and those given placebo. However, investigators did 40 report a benefit for patients treated with albendazole for other helminthic infections, although the prevalence of intestinal schistosomiasis in this part of Uganda can be considered mild..$^{48} \mathrm{~A}$ study in Ethiopia found evidence of a relation between deworming and decreased viral load..$^{90}$ Conversely, results from two Ugandan studies showed a transient increase in viral load and decreased CD4 cell counts after treatment, mainly in individuals with severe intestinal schistosomiasis, ${ }^{42,91}$ from a transient host immune activation after praziquantel treatment, yielding a situation that favours increased viral replication. Other results from Kenya, Malawi, Uganda, and Zambia have shown no effect of praziquantel on HIV viral markers. ${ }^{40,92,93}$

\section{Use of praziquantel in children}

The dosage for praziquantel in children (ie, at $40 \mathrm{mg} / \mathrm{kg}$ ) is a direct extrapolation from adults, and is probably flawed because no information about praziquantel 
pharmacokinetics and pharmacodynamics in young 1 are needed to ensure safe and effective dosing when children is available. Nonetheless, studies indicate drugs are given concurrently.

efficacy and safety on-the-ground with use of a praziquantel dosing pole, which allocates treatment on the basis of childrens' height [A: OK?]. ${ }^{912,94}$ However, 5 evidence from Uganda ${ }^{95}$ has raised questions about recommended dosing, which might be inadequate for the metabolism of pre-school-age children and about whether chlidren's immune systems are sufficiently developed to provide potent parasite clearance. This 10 effect on parasite clearance could be worsened by concurrent HIV infection or some other congenital or acquired immune deficiency.

Extrapolation of dose by weight from adults is particularly problematic because blood volumes, meta- 1 bolic rates, and extracellular volumes are better correlated with body surface area. As a result, drug doses normalised to the weight of adults can result in lower doses in young children than when normalised to body surface area. ${ }^{96}$ Developmental changes are also important; particularly 2 pertinent to praziquantel is the maturation of drug metabolism because the fetal liver contains only $30-40 \%$ of the CYP450 detoxification system content of adults, which typically ascends to a peak by age 10 years. ${ }^{97}$ These reduced enzyme concentrations might suggest slower drug clearance from the bloodstream in children, which is consistent with observations that drug concentrations are generally reported as higher in children than in adults. ${ }^{98}$

\section{An era of community chemotherapy: drug-drug interactions}

With the roll-out of HAART and increasing use of praziquantel in early childhood, ${ }^{99}$ there might be substantial benefit to treat both diseases simultaneously and as early as possible; however, some further consideration of drug interactions and side-effects would be advisable because of the many potential interactions between antiretroviral therapy and antiparasitic drugs. The cytochrome P450 super-family of enzymes is central to drug metabolism and drug-drug interactions, 4 particularly praziquantel. ${ }^{100}$ Praziquantel is rapidly absorbed and has more than $80 \%$ bioavailability after oral administration, ${ }^{101}$ with drug clearance predominantly occurring by first-pass metabolism of CYP1A2, CYP2C19, and CYP3A4, with a dominance of CYP3A. ${ }^{102,103}$ Based on 4 knowledge of drug metabolism, the expected effects of clinicians giving both HAART and praziquantel will probably differ dependent on which antiretroviral therapy drugs are used. For example, decreased praziquantel concentrations could occur if given concurrently with 50 non-nucleoside reverse transcriptase inhibitors nevirapine or efavirenz, so-called HIV backbone treatments. These drugs are CYP450 inducers. Coadministration of praziquantel with protease inhibitors, which tend to inhibit CYP450 metabolism, 5 could lead to increased praziquantel concentrations; ${ }^{104}$ thus, well designed studies of paediatric pharmacokinetics

Other drugs commonly used in sub-Saharan Africa are artemisinin-combination drugs and quinine derivatives for malaria, but based on their liver enzyme metabolism, ${ }^{105,106}$ neither is unlikely to affect praziquantel metabolism when given concomitantly. Antituberculous treatments (rifampicin, isoniazid, and clarithromycin) might have an effect on circulating praziquantel concentrations. Rifampicin is a potent inducer of CYP450, particularly CYP2C19 and CYP3A4, and in theory, this action could reduce circulating praziquantel concentrations. ${ }^{103}$ Isoniazid and clarithromycin might increase praziquantel circulating concentrations. ${ }^{107-109}$ Clarithromycin is recommended for multidrug-resistant infectio Sut if treatment with praziquantel was judged essential and, as an open conjecture, rifampicin could be stopped 1 weeks before praziquantel was given and then reinstated a day after the praziquantel regimenthen praziquantel might be able to be given, although repercussions of this regimen are not known and ethically questionable [A: OK? JS's corrections were unclear here. Please clarify]. ${ }^{107}$

Immune reconstitution inflammatory syndrome Immune reconstitution inflammatory syndrome, more recently referred to as immune reconstitution disease, is a well known disorder that can occur after initiation of HAART in some individuals. Immune reconstitution 30 disease is a collection of inflammatory disorders associated with paradoxical worsening of existing infectious processes, particularly opportunistic infections of HIV/AIDS. ${ }^{10}$ Clinicians are reporting an increasing number of immune reconstitution disease cases in association with parasitic diseases, with flare-ups of reactivating schistosomiasis being noted-evidenced by raised eosinophilia, hepatosplenomegaly, and colitis with polyposis. $^{45}$

In Zimbabwe, results of a 2008 study show significant o decreases in soluble tumour necrosis factor receptor II (a cytokine-associated marker linked with systemic inflammation) among patients with both HIV and schistosomiasis after they were given praziquantel..$^{41}$ This finding suggests a reduction in inflammatory responses after praziquantel, which might lead to decreased HIV viral replication and even attenuate the risk of immune reconstitution disease after HAART. Because no studies have been done in patients given HAART, this sphere remains to be explored in all age groups.

\section{HIV and schistosomiasis coinfection and childhood vaccinations}

After the expanded programme of vaccination, global vaccine coverage for children is increasing every year, ${ }^{19}$ whereas knowledge for the effects of coexisting childhood morbidities on response to vaccines is lagging behind, restricting vaccines' optimum effectiveness in on-the- 
ground settings. Although safe, vaccination in children with HIV is less immunogenic than in children without HIV,${ }^{11-113}$ and children with HIV who do achieve protective antibody titres can have a more rapid waning of vaccineinduced immunity. ${ }^{114}$

Children born to women who have parasitic diseases, including schistosomiasis, and have a decreased response to certain childhood vaccinations (eg, BCG ${ }^{115,116}$ ). A 2011 randomised controlled trial in Uganda showed no association between single praziquantel or albendazole treatment of late-term pregnant women and the response of their infants to BCG; ${ }^{117}$ it is unlikely that one maternal dose of praziquantel can erase fetal immune sensitisation to schistosome antigens. However, the question remains as to whether maternal parasite infection, and then immune-skewing by HIV, modifies or exacerbates disease among children who then acquire schistosomiasis early in life, and whether HIV and schistosomiasis have combined effects on the efficacy of later childhood vaccinations-all of these events can also be set against pubertal hormonal 20 production and its potential protection against schistosomiasis. ${ }^{118,119}$

\section{Delineating a research agenda}

As we have stated, there are several gaps in [A: We would 25 like to avoid use of our because of majestic plurals. OK?] knowledge about HIV and schistosomiasis coinfection in children, which is rather staggering. Within the planning context for future integrated health interventions, we firmly believe that there is a global duty to address 30 promptly the disparity between paediatric and adult research and, as conceptual guidance, we suggest a timeline for future paediatric HIV and schistosomiasis research, delineated into key developmental periods of the child (figure 3).

Before birth, there should be better documentation of the intricate relation between HIV and concurrent helminthiasis in mothers and unborn children, including efforts to develop non-invasive imagery methods or assays for detection of female genital schistosomiasis to 5 clarify the at-risk population. Pregnant women with female genital schistosomiasis should receive praziquantel and rates of HIV transmission from treated mothers to children should be recorded. The effect of untreated vertically transmitted HIV in children who contract schistosomiasis at an early age should be investigated along with their rate of progression to AIDS. The response to immunisations in children coinfected with HIV and schistosomiasis should be studied, with observation of children born to women with schistosomiasis. Researchers should investigate the extent of fetal immune priming and modulation during the antenatal period and how this priming affects risk of schistosomiasis disease and HIV progression later in life.

For children, the timing and successful occurrence of key stages as they progressively gain independence from their mothers is important. Interactions between HIV and schistosomiasis in causative mechanisms of anaemia, growth, retardation, decreased cognition, and decrease in overall quality of life need to be elucidated. Pharmacokinetics and pharmacodynamics of praziquantel efficacy in children should be investigated in field settings, as should drug-drug interactions of antiparasitic drugs used in preventive chemotherapy alongside HAART and antituberculous drugs.

Investigators should more precisely measure the physical changes and psychological challenges to attain wellbeing for older children and adolescents with chronic diseases such as HIV and schistosomiasis by doing culturally sensitive studies of issues surrounding the 35 beginning of sexual activity and minimisation of further risks of HIV transmission. Non-invasive methods for

\begin{tabular}{|c|c|c|c|c|}
\hline & \multicolumn{4}{|c|}{ Immune responses in children vertically infected with HIV followed by Schistosoma spp infection } \\
\hline \multicolumn{2}{|c|}{$\begin{array}{l}\text { Perinatal mortality associated with vertical HIV } \\
\text { transmission and severe immunosuppression } \\
\text { with early schistosomiasis }\end{array}$} & \multicolumn{3}{|c|}{$\begin{array}{l}\text { Impaired growth and development } \\
\text { Paediatric quality-of-life assessment } \\
\text { Cognitive performance }\end{array}$} \\
\hline $\begin{array}{l}\text { Maternal-child HIV } \\
\text { transmission risks } \\
\text { (ie, FUS) }\end{array}$ & \multirow{2}{*}{$\begin{array}{l}\text { Early interactions } \\
\text { in infants with HIV } \\
\text { or early Schistosoma } \\
\text { exposure }\end{array}$} & \multicolumn{2}{|c|}{$\begin{array}{l}\text { Evolving PZQ pharmacokinetics and pharmacodynamics and performance } \\
\text { Drug-drug interactions of PZQ with ARVs and anti-malarials }\end{array}$} & \multirow{3}{*}{$\begin{array}{l}\text { New diagnostic methods for FUS } \\
\text { Psychosocial hurdles affecting ART } \\
\text { compliance and initiation of sexuality } \\
\text { Interactions with secondary hormone }\end{array}$} \\
\hline \multirow{2}{*}{$\begin{array}{l}\text { Immune-modulations in } \\
\text { fetus from mother with } \\
\text { HIV or schistosomiasis }\end{array}$} & & \multicolumn{2}{|c|}{$\begin{array}{l}\text { Early schistosomiasis disease in children with HIV and HIV-exposed children } \\
\text { Progression to AIDS alongside concurrent schistosomiasis }\end{array}$} & \\
\hline & \multicolumn{3}{|c|}{ Response to childhood vaccinations in children with HIV-schistosomiasis } & \\
\hline$\downarrow$ & $\checkmark$ & $\downarrow$ & $\downarrow$ & $\nabla$ \\
\hline Prenatal & $\begin{array}{l}\text { Infants } \\
\text { (birth-1 years) }\end{array}$ & $\begin{array}{l}\text { Preschool age child } \\
\text { (aged 2-5 years) }\end{array}$ & $\begin{array}{l}\text { School-age child } \\
\text { (aged 6-13years) }\end{array}$ & $\begin{array}{l}\text { Adolescents } \\
\text { (older than } 14 \text { years) }\end{array}$ \\
\hline
\end{tabular}

Figure 3: Suggested topics for research of paediatric HIV and schistosomiasis infection in dual endemic areas of sub-Saharan Africa $\mathrm{FUS}=$ female genital schistosomiasis. $\mathrm{PZQ}=$ praziquantel. $\mathrm{ARV}=$ antiretrovirals. 


\section{Search strategy and selection criteria}

We identified papers through searches of PubMed and Google Scholar for articles published from Jan 1, 1990, to July 30, 2013, with use of the terms "HIV", "AIDS", "schistosomiasis", "children", "paediatrics", "Africa", "morbidity", and "immunology". We applied additional terms and filters for "HIV-schistosomiasis co-infection". From the results of this search, we reviewed articles published in English, French, and Spanish.

detection of genital schistosomiasis in both sexes and clinical staging schedules for disease management are 1 needed. Pubertal hormonal production and its potential protection against schistosomiasis progression and reinfection rates should be studied. Social determinants of health encompassing behavioural and psychosocial problems should be recorded to ensure the development 20 and application of tailored interventions.

\section{Conclusion}

Provision of optimum public health care for paired management of HIV and schistosomiasis in sub-Saharan 25 Africa might be more than a decade away. Failure to develop and implement a realistic research agenda for infected children will result in the neglect of the youngest children who might be at particular risk for increased HIV transmission, HIV progression, and impaired 3 response to drugs. We hope that this review will stimulate a collective agenda to ensure that real progress will be made in the long-term management of paediatric HIV and schistosomiasis coinfection.

\section{Contributors}

ALB and JRS conceived the ideas for this Review, which were then developed in discussions with CK, JS, SA, JCS-F, and MB. SA and ALB assembled the bibliography and produced the table and figures, with assistance from JCS-F and MB. All authors contributed to the Review, with CK and JS particularly focusing on quality-of-life and pharmacology aspects, respectively.

\section{Conflicts of interest}

We declare that we have no conflicts of interest.

Acknowledgments

AB, JCS-F, MB, and JRS received support from the Wellcome Trust, UK.

References

1 Hotez PJ, Kamath A. Neglected tropical diseases in sub-saharan Africa: review of their prevalence, distribution, and disease burden. PLoS Negl Trop Dis 2009; 3: e412.

2 Gryseels B, Polman K, Clerinx J, Kestens L. Human schistosomiasis. Lancet 2006; 368: 1106-18.

3 UNAIDS. Global report: UNAIDS report on the global AIDS epidemic 2010. Geneva: United Nations Programme on HIV/AIDS, 2010.

4 Boender TS, Sigaloff KC, Kayiwa J, et al. Barriers to initiation of pediatric HIV treatment in Uganda: a mixed-method study. Aids Res Treat 2012; 2012: 817506.

5 WHO. WHO recommendations on the diagnosis of HIV infection in infants and children. Geneva: World Health Organization, 2010.

6 WHO. Dept of HIV/AIDS. Antiretroviral therapy of HIV infection in infants and children: towards universal access: recommendations for a public health approach. Geneva: World Health Organization,
12007.

7 UNAIDS. Progresss report on the global plan towards the elimination of new HIV infections among children by 2015 and keeping their mothers alive. Geneva: United Nations Programme on HIV/AIDS, 2011

58 Garba A, Barkiré N, Djibo A, et al. Schistosomiasis in infants and preschool-aged children: infection in a single Schistosoma haematobium and a mixed $S$ haematobium-S mansoni foci of Niger. Acta Trop 2010; 115: 212-19.

9 Sousa-Figueiredo JC, Pleasant J, Day M, et al. Treatment of intestinal schistosomiasis in Ugandan preschool children: best diagnosis, treatment efficacy and side-effects, and an extended praziquantel dosing pole. Int Health 2010; 2: 103-13.

10 Crompton DWT, WHO. Preventive chemotherapy in human helminthiasis: coordinated use of anthelminthic drugs in control interventions: a manual for health professionals and programme managers. Geneva: World Health Organization, 2006.

11 Fenwick A, Webster JP, Bosque-Oliva E, et al. The Schistosomiasis Control Initiative (SCI): rationale, development and implementation from 2002-2008. Parasitology 2009; 136: 1719-30.

12 Stothard JR, Sousa-Figueiredo JC, Betson M, et al. Closing the praziquantel treatment gap: new steps in epidemiological monitoring and control of schistosomiasis in African infants and preschool-aged children. Parasitology 2011; 138: 1593-606.

13 WHO. Report of a meeting to review the results of studies on the treatment of schistosomiasis in preschool-aged children. Geneva: World Health Organization, 2011.

14 Fairley J. Bilharzia. A history of imperial tropical medicine. Cambridge: Cambridge University Press, 1991.

15 King CH. Parasites and poverty: the case of schistosomiasis. Acta Trop 2010; 113: 95-104.

16 Coates TJ, Richter L, Caceres C. Behavioural strategies to reduce HIV transmission: how to make them work better. Lancet 2008; 372: 669-84.

17 Bruun B, Aagaard-Hansen J, for the UNICEF/UNDP/World Bank/ WHO Special Programme for Research and Training in Tropical Diseases. The social context of schistosomiasis and its control: an introduction and annotated bibliography. Geneva: World Health Organization, 2008.

18 Utzinger J. A research and development agenda for the control and elimination of human helminthiases. PLoS Negl Trop Dis 2012; 6: e1646.

19 WHO. Malaria and HIV/AIDS interactions and implications: conclusions of a technical consultation convened by WHO, 23-25 June 2004. Geneva: World Health Organization, 2004.

3520 CDC. Pneumocystis pneumonia-Los Angeles. MMWR Morb Mortal Wkly Rep 1981; 30: 250-52.

21 Quinn TC, Mann JM, Curran JW, Piot P. AIDS in Africa: an epidemiologic paradigm. Science 1986; 234: 955-63.

22 Odogwu SE, Ramamurthy NK, Kabatereine NB, et al. Schistosoma mansoni in infants (aged $<3$ years) along the Ugandan shoreline of Lake Victoria. Ann Trop Med Parasitol 2006; 100: 315-26.

23 Sousa-Figueiredo JC, Basáñez MG, Mgeni AF, Khamis IS, Rollinson D, Stothard JR. A parasitological survey, in rural Zanzibar, of pre-school children and their mothers for urinary schistosomiasis, soil-transmitted helminthiases and malaria, with observations on the prevalence of anaemia. Ann Trop Med Parasitol 2008; 102: 679-92.

4524 Verani JR, Abudho B, Montgomery SP, et al. Schistosomiasis among young children in Usoma, Kenya. Am J Trop Med Hyg 2011; 84: 787-91.

25 Bustinduy AL, Thomas CL, Fiutem JJ, et al. Measuring fitness of Kenyan children with polyparasitic infections using the 20-meter shuttle run test as a morbidity metric. PLoS Negl Trop Dis 2011; 5: e1213.

26 Ezeamama AE, Friedman JF, Acosta LP, et al. Helminth infection and cognitive impairment among Filipino children. Am J Trop Med Hyg 2005; 72: 540-48.

27 Stephenson LS, Latham MC, Adams EJ, Kinoti SN, Pertet A. Physical fitness, growth and appetite of Kenyan school boys with hookworm, Trichuris trichiura and Ascaris lumbricoides infections are improved four months after a single dose of albendazole. J Nutr 1993; 123: 1036-46.

28 King $\mathrm{CH}$, Dangerfield-Cha $\mathrm{M}$. The unacknowledged impact of 
chronic schistosomiasis. Chronic Illn 2008; 4: 65-79.

29 King CH, Dickman K, Tisch DJ. Reassessment of the cost of chronic helmintic infection: a meta-analysis of disability-related outcomes in endemic schistosomiasis. Lancet 2005; 365: 1561-69.

30 Webb EL, Ekii AO, Pala P. Epidemiology and immunology of helminth-HIV interactions. Curr Opin HIV AIDS 2012; 7: 245-53.

31 Secor WE, Sundstrom JB. Below the belt: new insights into potential complications of HIV-1/schistosome coinfections. Curr Opin Infect Dis 2007; 20: 519-23.

32 Stothard JR, Chiodini P, Booth M. Progress in paediatric parasitology: a preface to a topic focusing on ever younger subjects. Parasitology 2011; 138: 1453-58.

33 Hesseling AC, Schaaf HS, Gie RP, Starke JR, Beyers N. A critical review of diagnostic approaches used in the diagnosis of childhood tuberculosis. Int J Tuberc Lung Dis 2002; 6: 1038-45.

34 Karanja DM, Colley DG, Nahlen BL, Ouma JH, Secor WE. Studies on schistosomiasis in western Kenya: I. Evidence for immunefacilitated excretion of schistosome eggs from patients with Schistosoma mansoni and human immunodeficiency virus coinfections. Am J Trop Med Hyg 1997; 56: 515-21.

35 Fontanet AL, Woldemichael T, Sahlu T, et al. Epidemiology of HIV and Schistosoma mansoni infections among sugar-estate residents in Ethiopia. Ann Trop Med Parasitol 2000; 94: 145-55.

36 N'Zoukoudi-N'Doundou MY, Dirat I, Akouala JJ, Penchenier L, Makuwa M, Rey JL. [Bilharziasis and human immunodeficiency virus infection in Congo]. Med Trop (Mars) 1995; 55: 249-51.

37 Kallestrup P, Zinyama R, Gomo E, et al. Schistosomiasis and HIV-1 infection in rural Zimbabwe: implications of coinfection for excretion of eggs. J Infect Dis 2005; 191: 1311-20.

38 Sabah AA, Fletcher C, Webbe G, Doenhoff MJ. Schistosoma mansoni: reduced efficacy of chemotherapy in infected T-celldeprived mice. Exp Parasitol 1985; 60: 348-54.

39 Ayash-Rashkovsky M, Chenine AL, Steele LN, et al. Coinfection with Schistosoma mansoni reactivates viremia in rhesus macaques with chronic simian-human immunodeficiency virus clade C infection. Infect Immun 2007; 75: 1751-56.

40 Hosseinipour MC, Napravnik S, Joaki G, et al. HIV and parasitic infection and the effect of treatment among adult outpatients in Malawi. J Infect Dis 2007; 195: 1278-82.

41 Erikstrup C, Kallestrup P, Zinyama-Gutsire RB, et al. Schistosomiasis and infection with human immunodeficiency virus 1 in rural Zimbabwe: systemic inflammation during co-infection and after treatment for schistosomiasis. Am J Trop Med Hyg 2008; 79: 331-37.

42 Brown M, Mawa PA, Joseph S, et al. Treatment of Schistosoma mansoni infection increases helminth-specific type 2 cytokine responses and HIV-1 loads in coinfected Ugandan adults. J Infect Dis 2005; 191: 1648-57.

43 Kallestrup P, Zinyama R, Gomo E, et al. Schistosomiasis and HIV in rural Zimbabwe: efficacy of treatment of schistosomiasis in individuals with HIV coinfection. Clin Infect Dis 2006; 42: 1781-89.

44 Bangirana P, Musisi S, Boivin MJ, et al. Malaria with neurologica involvement in Ugandan children: effect on cognitive ability, academic achievement and behaviour. Malar J 2011; 10: 334

45 Smith R, Malee K, Leighty R, et al, for the Women and Infants Transmission Study Group. Effects of perinatal HIV infection and associated risk factors on cognitive development among young children. Pediatrics 2006; 117: 851-62.

46 De Cock KM, Fowler MG, Mercier E, et al. Prevention of mother-to-child HIV transmission in resource-poor countries: translating research into policy and practice. JAMA 2000; 283: 1175-82.

47 Gallagher M, Malhotra I, Mungai PL, et al. The effects of maternal helminth and malaria infections on mother-to-child HIV transmission. AIDS 2005; 19: 1849-55.

48 Webb EL, Kyosiimire-Lugemwa J, Kizito D, et al. The effect of anthelmintic treatment during pregnancy on HIV plasma viral load: results from a randomized, double-blind, placebo-controlled trial in Uganda. J Acquir Immune Defic Syndr 2012; 60: 307-13.

49 Bearer CF. How are children different from adults? Environ Health Perspect 1995; 103: 7-12.

50 Arpadi SM, Cuff PA, Kotler DP, et al. Growth velocity, fat-free mass and energy intake are inversely related to viral load in HIV-infected children. J Nutr 2000; 130: 2498-502.
151 Friedman JF, Kanzaria HK, Acosta LP, et al. Relationship between Schistosoma japonicum and nutritional status among children and young adults in Leyte, the Philippines. Am J Trop Med Hyg 2005 72: $527-33$.

52 Routledge PA. Pharmacokinetics in children.J Antimicrob Chemother 1994; 34 (suppl): 19-24.

53 Doenhoff MJ, Cioli D, Utzinger J. Praziquantel: mechanisms of action, resistance and new derivatives for schistosomiasis. Curr Opin Infect Dis 2008; 21: 659-67.

54 Secor WE. Interactions between schistosomiasis and infection with HIV-1. Parasite Immunol 2006; 28: 597-603.

55 Black CL, Mwinzi PN, Muok EM, et al. Influence of exposure history on the immunology and development of resistance to human Schistosomiasis mansoni. PLoS Negl Trop Dis 2010; 4: e637.

56 Mott KE, Dixon H, Osei-Tutu E, England EC. Relation between intensity of Schistosoma haematobium infection and clinical haematuria and proteinuria. Lancet 1983; 1: 1005-08.

57 Jamison DT, Mosley WH. Disease control priorities in developing

15 countries: health policy responses to epidemiological change. Am J Public Health 1991; 81: 15-22.

58 King $\mathrm{CH}$, Bertino AM. Asymmetries of poverty: why global burden of disease valuations underestimate the burden of neglected tropical diseases. PLoS Negl Trop Dis 2008; 2: e209.

59 Zanoni BC, Phungula T, Zanoni HM, France H, Feeney ME. Risk factors associated with increased mortality among HIV infected children initiating antiretroviral therapy (ART) in South Africa. PLOS ONE 2011; 6: e22706.

60 Sutcliffe CG, van Dijk JH, Munsanje B, et al. Risk factors for pre-treatment mortality among HIV-infected children in rural Zambia: a cohort study. PLoS ONE 2011; 6: e29294.

61 Friedman JF, Kanzaria HK, McGarvey ST. Human schistosomiasis and anemia: the relationship and potential mechanisms. Trends Parasitol 2005; 21: 386-92.

62 Stephenson LS, Latham MC, Kurz KM, Kinoti SN, Oduori ML, Crompton DW. Relationships of Schistosoma hematobium, hookworm and malarial infections and metrifonate treatment to hemoglobin level in Kenyan school children. Am J Trop Med Hyg 1985; 34: 519-28.

63 Mupfasoni D, Karibushi B, Koukounari A, et al. Polyparasite helminth infections and their association to anaemia and undernutrition in Northern Rwanda. PLoS Negl Trop Dis 2009; 3: e517.

64 Koukounari A, Estambale BB, Njagi JK, et al. Relationships between anaemia and parasitic infections in Kenyan schoolchildren: a Bayesian hierarchical modelling approach. Int J Parasitol 2008; 38: 1663-71.

65 Simoonga C, Kazembe LN, Kristensen TK, et al. The epidemiology and small-scale spatial heterogeneity of urinary schistosomiasis in Lusaka province, Zambia. Geospat Health 2008; 3: 57-67.

66 Saathoff E, Olsen A, Magnussen P, Kvalsvig JD, Becker W, Appleton CC. Patterns of Schistosoma haematobium infection, impact of praziquantel treatment and re-infection after treatment in a cohort of schoolchildren from rural KwaZulu-Natal/South Africa. $B M C$ Infect Dis 2004; 4: 40.

4067 King CH. Long-term outcomes of school-based treatment for control of urinary schistosomiasis: a review of experience in Coast Province, Kenya. Mem Inst Oswaldo Cruz 2006; 101 (suppl): 299-306.

68 Secor WE, Karanja DM, Colley DG. Interactions between schistosomiasis and human immunodeficiency virus in Western Kenya. Mem Inst Oswaldo Cruz 2004; 99 (suppl): 93-95.

4569 Mwinzi PN, Karanja DM, Kareko I, et al. Short report: evaluation of hepatic fibrosis in persons co-infected with Schistosoma mansoni and human immunodeficiency virus 1. Am J Trop Med Hyg 2004; 71: 783-86.

70 Jourdan PM, Holmen SD, Gundersen SG, Roald B, Kjetland EF. HIV target cells in Schistosoma haematobium-infected female genital mucosa. Am J Trop Med Hyg 2011; 85: 1060-64.

5071 Jourdan PM, Roald B, Poggensee G, Gundersen SG, Kjetland EF. Increased vascularity in cervicovaginal mucosa with Schistosoma haematobium infection. PLoS Negl Trop Dis 2011; 5: e1170.

72 Mwinzi PN, Karanja DM, Colley DG, Orago AS, Secor WE. Cellular immune responses of schistosomiasis patients are altered by human immunodeficiency virus type 1 coinfection. J Infect Dis 2001; 184: 488-96.

73 McElroy MD, Elrefaei M, Jones N, et al. Coinfection with Schistosoma mansoni is associated with decreased HIV-specific cytolysis and increased IL-10 production. J Immunol 2005; 174: 5119-23. 
74 Downs JA, Mguta C, Kaatano GM, et al. Urogenital schistosomiasis 195 Sousa-Figueiredo JC, Betson M, Atuhaire A, et al. Performance in women of reproductive age in Tanzania's Lake Victoria region. Am J Trop Med Hyg 2011; 84: 364-69.

75 Kjetland EF, Ndhlovu PD, Gomo E, et al. Association between genital schistosomiasis and HIV in rural Zimbabwean women. AIDS 2006; 20: 593-600.

76 Ndhlovu PD, Mduluza T, Kjetland EF, et al. Prevalence of urinary schistosomiasis and HIV in females living in a rural community of Zimbabwe: does age matter? Trans R Soc Trop Med Hyg 2007; 101: 433-38.

77 Leutscher P, Ramarokoto CE, Reimert C, Feldmeier H, Esterre P, Vennervald BJ. Community-based study of genital schistosomiasis in men from Madagascar. Lancet 2000; 355: 117-18.

78 Leutscher PD, Pedersen M, Raharisolo C, et al. Increased prevalence of leukocytes and elevated cytokine levels in semen from Schistosoma haematobium-infected individuals. J Infect Dis 2005; 191: 1639-47.

79 Chenine AL, Shai-Kobiler E, Steele LN, et al. Acute Schistosoma mansoni infection increases susceptibility to systemic SHIV clade C infection in rhesus macaques after mucosal virus exposure. PLoS Negl Trop Dis 2008; 2: e265.

80 Dietze KK, Zelinskyy G, Gibbert K, et al. Transient depletion of regulatory $\mathrm{T}$ cells in transgenic mice reactivates virus-specific CD8+ $\mathrm{T}$ cells and reduces chronic retroviral set points. Proc Natl Acad Sci USA 2011; 108: 2420-25.

81 Pesce JT, Ramalingam TR, Mentink-Kane MM, et al. Arginase-1expressing macrophages suppress Th2 cytokine-driven inflammation and fibrosis. PLoS Pathog 2009; 5: e1000371.

82 Cloke TE, Garvey L, Choi BS, et al. Increased level of arginase activity correlates with disease severity in HIV-seropositive patients. $J$ Infect Dis 2010; 202: 374-85.

83 Secor WE, Shah A, Mwinzi PM, Ndenga BA, Watta CO, Karanja DM. Increased density of human immunodeficiency virus type 1 coreceptors CCR5 and CXCR4 on the surfaces of CD4(+) T cells and monocytes of patients with Schistosoma mansoni infection. Infect Immun 2003; 71: 6668-71.

84 Brindley PJ, Sher A. The chemotherapeutic effect of praziquantel against Schistosoma mansoni is dependent on host antibody response. J Immunol 1987; 139: 215-20.

85 Karanja DM, Boyer AE, Strand M, et al. Studies on schistosomiasis in western Kenya: II. Efficacy of praziquantel for treatment of schistosomiasis in persons coinfected with human immunodeficiency virus-1. Am J Trop Med Hyg 1998; 59: 307-11.

86 Mwanakasale V, Vounatsou P, Sukwa TY, Ziba M, Ernest A, Tanner M. Interactions between Schistosoma haematobium and human immunodeficiency virus type 1: the effects of coinfection on 35 treatment outcomes in rural Zambia. Am J Trop Med Hyg 2003; 69: 420-28.

87 Walson JL, Herrin BR, John-Stewart G. Deworming helminth co-infected individuals for delaying HIV disease progression. Cochrane Database Syst Rev 2009; 3: CD006419.

88 Sangaré LR, Herrin BR, John-Stewart G, Walson JL. Species-specific treatment effects of helminth/HIV-1 co-infection: a systematic review and meta-analysis. Parasitology 2011; 138: 1546-58.

89 Kallestrup P, Zinyama R, Gomo E, et al. Schistosomiasis and HIV-1 infection in rural Zimbabwe: effect of treatment of schistosomiasis on CD4 cell count and plasma HIV-1 RNA load. J Infect Dis 2005; 192: 1956-61.

90 Wolday D, Mayaan S, Mariam ZG, et al. Treatment of intestinal worms is associated with decreased HIV plasma viral load. J Acquir Immune Defic Syndr 2002; 31: 56-62.

91 Elliott AM, Mawa PA, Joseph S, et al. Associations between helminth infection and CD4+ T cell count, viral load and cytokine responses in HIV-1-infected Ugandan adults. Trans R Soc Trop Med Hyg 2003; 97: 103-08.

92 Lawn SD, Karanja DM, Mwinzia P, et al. The effect of treatment of schistosomiasis on blood plasma HIV-1 RNA concentration in coinfected individuals. AIDS 2000; 14: 2437-43.

93 Modjarrad K, Zulu I, Redden DT, et al. Treatment of intestinal helminths does not reduce plasma concentrations of HIV-1 RNA in coinfected Zambian adults. J Infect Dis 2005; 192: 1277-83.

94 Mutapi F, Rujeni N, Bourke C, et al. Schistosoma haematobium treatment in 1-5 year old children: safety and efficacy of the antihelminthic drug praziquantel. PLoS Negl Trop Dis 2011; 5: e1143.

and safety of praziquantel for treatment of intestinal schistosomiasis in infants and preschool children. PLoS Negl Trop Dis 2012; 6: e1864.

96 Fox EBF. Drug Therapy in Neonates and Pediatric Patients. In: Abernethy DR, Daniels CE, Dedrick RL, Markey SP, eds. 5 Principles of Clinical Pharmacology, 2nd edn. Amsterdam: Elsevier, 2007.

97 Shimada T, Yamazaki H, Mimura M, et al. Characterization of microsomal cytochrome P450 enzymes involved in the oxidation of xenobiotic chemicals in human fetal liver and adult lungs. Drug Metab Dispos 1996; 24: 515-22.

1098 Hines RN, McCarver DG. The ontogeny of human drug-metabolizing enzymes: phase I oxidative enzymes. J Pharmacol Exp Ther 2002; 300: 355-60.

99 Coutinho HM, Acosta LP, McGarvey ST, et al. Nutritional status improves after treatment of Schistosoma japonicum-infected children and adolescents. J Nutr 2006; 136: 183-88.

100 Gonzalez FJ. Overview of experimental approaches for study of drug metabolism and drug-drug interactions. In: Li AP, ed. Drug-drug interactions: scientific and regulatory perspectives. Waltham: Academic Press, 1997: 255-269.

101 Patzschke K, Pütter J, Wegner LA, Horster FA, Diekmann HW Serum concentrations and renal excretion in humans after oral administration of praziquantel-results of three determination methods. Eur J Drug Metab Pharmacokinet 1979; 4: 149-56

102 Li XQ, Björkman A, Andersson TB, Gustafsson LL, Masimirembwa CM. Identification of human cytochrome $\mathrm{P}(450) \mathrm{s}$ that metabolise anti-parasitic drugs and predictions of in vivo drug hepatic clearance from in vitro data. Eur J Clin Pharmacol 2003; 59: 429-42.

103 Ridtitid W, Wongnawa M, Mahatthanatrakul W, Punyo J, Sunbhanich M. Rifampin markedly decreases plasma concentrations of praziquantel in healthy volunteers. Clin Pharmacol Ther 2002; 72: 505-13.

104 Dooley KE, Flexner C, Andrade AS. Drug interactions involving combination antiretroviral therapy and other anti-infective agents: repercussions for resource-limited countries. J Infect Dis 2008; 198: 948-61.

105 Bapiro TE, Egnell AC, Hasler JA, Masimirembwa CM. Application of higher throughput screening (HTS) inhibition assays to evaluate the interaction of antiparasitic drugs with cytochrome P450s. Drug Metab Dispos 2001; 29: 30-35.

106 Bapiro TE, Sayi J, Hasler JA, et al. Artemisinin and thiabendazole are potent inhibitors of cytochrome P450 1A2 (CYP1A2) activity in humans. Eur J Clin Pharmacol 2005; 61: 755-61.

107 Sweetman SC. Martindale: The Complete Drug Reference, 37th ed. London: Pharmaceutical Press, 2012.

108 Nishimura Y, Kurata N, Sakurai E, Yasuhara H. Inhibitory effect of antituberculosis drugs on human cytochrome P450-mediated activities. J Pharmacol Sci 2004; 96: 293-300.

109 Sandoz. Clarithromycin S. Camberley: Sandoz, 2012.

110 French MA, Lenzo N, John M, et al. Immune restoration disease after the treatment of immunodeficient HIV-infected patients with highly active antiretroviral therapy. HIV Med 2000; 1: 107-15.

111 Klugman KP, Madhi SA, Huebner RE, Kohberger R, Mbelle N, Pierce N, for the Vaccine Trialists Group. A trial of a 9-valent pneumococcal conjugate vaccine in children with and those without HIV infection. N Engl J Med 2003; 349: 1341-48.

112 Bertolini DV, Costa LS, van der Heijden IM, Sato HK, Marques HH. Immunogenicity of a meningococcal serogroup $C$ conjugate vaccine in HIV-infected children, adolescents, and young adults. Vaccine 2012; 30: 5482-86.

113 Scott P, Moss WJ, Gilani Z, Low N. Measles vaccination in HIV-infected children: systematic review and meta-analysis of safety and immunogenicity. J Infect Dis 2011; 204 (suppl): S164-78.

114 Sutcliffe CG, Moss WJ. Do children infected with HIV receiving HAART need to be revaccinated? Lancet Infect Dis 2010; 10: 630-42.

115 Labeaud AD, Malhotra I, King MJ, King CL, King CH. Do antenatal parasite infections devalue childhood vaccination? PLoS Negl Trop Dis 2009; 3: e442.

55116 Malhotra I, Mungai P, Wamachi A, et al. Helminth- and Bacillus Calmette-Guérin-induced immunity in children sensitized in utero to filariasis and schistosomiasis. J Immunol 1999; 162: 6843-48. 
117 Webb EL, Mawa PA, Ndibazza J, et al. Effect of single-dose anthelmintic treatment during pregnancy on an infant's response to immunisation and on susceptibility to infectious diseases in infancy: a randomised, double-blind, placebo-controlled trial. Lancet 2011; 377: 52-62.

118 Brown M, Kizza M, Watera C, et al. Helminth infection is not associated with faster progression of HIV disease in coinfected adults in Uganda. $J$ Infect Dis 2004; 190: 1869-79.

119 Kurtis JD, Friedman JF, Leenstra T, et al. Pubertal development predicts resistance to infection and reinfection with Schistosoma japonicum. Clin Infect Dis 2006; 42: 1692-98. 